\title{
Decision-Making Framework for Validation of Data Collection Process in a Survey with GPS Data
}

\author{
You Ari Faeni ${ }^{1}$, Fadhil Hidayat ${ }^{2}$ \\ $\left\{\right.$ you@s.itb.ac.id ${ }^{1}$, fadhil@itb.ac.id ${ }^{2}$ \} \\ Bandung Institute of Technology, Bandung, Indonesia ${ }^{1,2}$
}

\begin{abstract}
This study uses Systematic Literature Review (SLR) to understand about research trends, methods, and data used in decision-making with GPS data. After reviewing 27 chosen journals and proceedings, this study concludes that there are several methods used to decide with GPS data such as decision tree, random forest, neural network, and support vector machine (SVM). Health, environment, Transportation, and agriculture are several fields of business that used GPS data to make a decision. The data analyzed consist of position, time, speed, track, and distance. Based on SLR result, we propose a method to validate the data collection process of a survey using three methods (SVM, decision tree and random forest) will be used to analyze the position, time, track and personal data of the surveyor.
\end{abstract}

Keywords: Decision Making, Systematic Literature Review, GPS data, Validation of a survey

\section{Introduction}

Survey is a method of gathering data from a group representing the population according to specific methodology [1]. Based on the method used, survey divided into two types, namely survey by Probability Sampling and survey by Non-Probability Sampling. Probability sampling is random sampling method to provide equal opportunities to each member of the population to be a sample. In Non-Probability Sampling Methods, Sampling is not random. To draw conclusions from population size, Probability Sampling is the most appropriate method to use [2]. There are several surveys using Probability Sampling methods such as SUSENAS (National Social Economic Survey), SAKERNAS (National Labor Force Survey), Cost of Living Survey.

Probability sampling method surveys consists of two phases of data collection, Updating/Listing and Complete Enumeration. Updating/Listing is a method to obtain preliminary information from the members of the population in a particular area. This information then used to perform sampling. A complete enumeration is the data collection process by asking all of the questions on the questionnaire to get the complete information of the selected sample.

A surveyor usually has the responsibility of 20-30 respondents and the supervisors responsible for 3-4 surveyor. Time used to collect data of the survey varied between 3-10 days 
depending on the number of respondents who should be enumerated and the level of difficulty of each survey. The complexity of the process of updating and complete enumeration sometimes cause various problems such as; Surveyors do not do the updating directly to the homes of respondents (door to door), so that the initial information as a basis for sampling inaccurate; Surveyor conducting the interview quickly, so that the resulting data is incomplete; Some surveyors fill out the questionnaire without coming to the respondent's house (not door to door); Supervisors cannot always accompany surveyors to collect data because they have to supervise 3 people simultaneously; The supervisor does not have a concrete measure to ask the enumerator to do a re-enumeration.

Based on the data available in 5 districts in South Sumatra province, the updated data that done by the surveyor not door to door has an error rate of $30-50 \%$ while the surveyor who updates door to door has an error rate of $0-10 \%$. Other data shows that a surveyor conduct a complete enumeration not door to door has an error rate of questionnaires of $40 \%-60 \%$, whereas the surveyor conducting door to door enumeration only has an error rate of $0-10 \%$. Surveyor usually does the process of updating and enumeration not door to door when inspectors have not accompanied the surveyor.

These problems usually discovered during the data processing process, so a re-visit was needed to correct these errors. Additional time required outside the survey schedule, so the data processing process hampered due to waiting for repairs. As a result, the costs needed increase and cause the release time of the survey results to reverse.

To overcome this problem, a new mechanism for validating the complete data collection (updating and enumeration) needed in a survey. The validation mechanism able to detect and provide recommendations on how to solve the problem found. Validation is an essential process for determining whether a process/activities are in accordance with existing procedures. Based on previous research, decision-making with GPS data is an appropriate method used to validate the data collection process in a survey.

Decision-making with GPS data involves an ongoing process of inference, the results of GPS data processing and interpretation of the information produced. In the decision-making GPS applications needed for example, choosing the fastest route, the determination of the long journey, tracking people, vehicles and even livestock and detect activities and behavior.

The purpose of this paper is to provide more profound knowledge about decision-making with GPS data. This study conducted a literature review using a Systematic Literature Review (SLR). SLR can help find a solution by reviewing the relevant research beforehand. The purpose of this study is to understand the research trends, methods, and architectures used in predictive analytics with IoT. To get comprehensive results, this research was done on some literature published in popular journals database, for example, IEEE Xplore, Scopus, ACM, and Springerlink from the year 2010 to 2019.

This paper consists of four sections. Section 2 explains the survey process, the validation process-related research, an explanation of the SLR, research questions and search results of the SLR. Section 3 presents the results of a literature review on methods, trends, and data used in decision-making with the GPS data and the position of research to be conducted by the SLR. Section 4 contains the conclusion of a literature review with the SLR. 


\section{Research Methodology}

\subsection{Process of a survey}

Figure 1. shows the process of collecting data in a survey. The first process is updating, which takes between 3-6 days. Furthermore, the updated data is used to conduct sampling. The next process is to collect complete information from selected samples by asking all questions in the questionnaire to the respondents. Finally, inputting data into the database and analyzing the data from the enumeration until it becomes specific indicators.

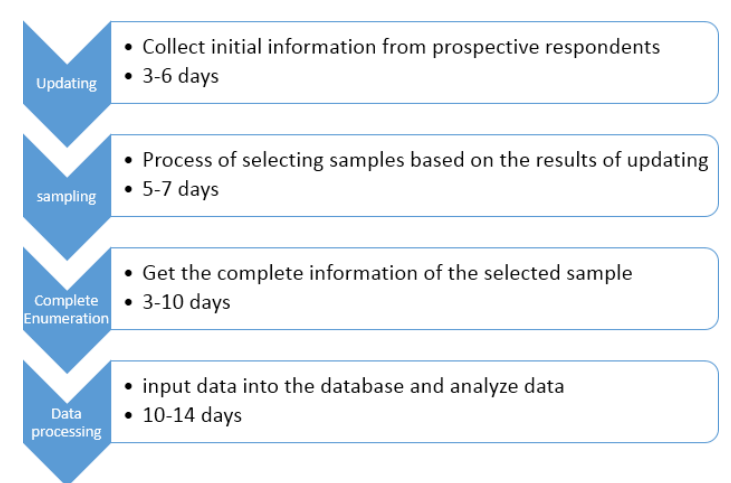

Fig. 1. Process of a survey.

\subsection{Validation Process}

Validation process is the most important step in the process of validating the process of collecting data in a survey. Validation process can be used to evaluate the accuracy of an activity and it is in accordance with the desired goal. at this stage several studies on validation will be discussed using several methods and certain data that can be seen in the Table 1 .

Table 1. Research About Validation.

\begin{tabular}{|c|c|c|c|c|}
\hline & Zhenyu (2006) & $\begin{array}{l}\text { Garrell } \\
(2010)\end{array}$ & $\begin{array}{l}\text { Haiman } \\
(2016)\end{array}$ & $\begin{array}{l}\text { Rajest } \\
\text { (2018) }\end{array}$ \\
\hline $\begin{array}{l}\text { Research } \\
\text { Objectives }\end{array}$ & $\begin{array}{l}\text { Validation with } \\
\text { hybrid dynamic } \\
\text { simulation }\end{array}$ & $\begin{array}{l}\text { Validation robot } \\
\text { behavior }\end{array}$ & $\begin{array}{l}\text { Validation for } \\
\text { hurricane loss } \\
\text { model }\end{array}$ & $\begin{array}{l}\text { Wave masurement } \\
\text { validation of wave } \\
\text { glider }\end{array}$ \\
\hline Data & $\begin{array}{l}\text { Voltage, real power } \\
\text { and reactive power }\end{array}$ & $\begin{array}{l}\text { Image, number of } \\
\text { steps, size of step }\end{array}$ & $\begin{array}{l}\text { Speed, Time, } \\
\text { location }\end{array}$ & $\begin{array}{l}\text { Wave height, } \\
\text { period, location, } \\
\text { direction }\end{array}$ \\
\hline $\begin{array}{l}\text { Data collect } \\
\text { from }\end{array}$ & $\begin{array}{l}\text { WECC } 1500 \mathrm{MW} \\
\text { generation loss }\end{array}$ & Video cctv & $\begin{array}{l}\text { Sensor data stored } \\
\text { in database }\end{array}$ & GPS, wave glider \\
\hline Environment & - & Indoor & Outdorr & Outdoor \\
\hline $\begin{array}{l}\text { Analysis } \\
\text { method }\end{array}$ & Statistical method & Statistical method & Probable max loss & Statistical method \\
\hline
\end{tabular}

Based on the table I, we knows that study of validation using various types of tools and data. Zhenyu presents a model validation methodology with a hybrid dynamic simulation. The 
authors use two application instances on generator and load model validation to show the validity of their methodology in the field of power engineering. Garrell used video record form CCTV to validate robot behavior compare with human motion behavior. Haiman study about validation of hurricane loss model by analyze data from sensor. Rajest study about wave measurement validation of wave glider use GPS data such as location, height, and direction. Research on validation of the process of collecting data in a survey will use GPS data because it has characteristics that are almost the same as research from Rajest.

\subsection{Systematic Literature Review}

Systematic Literature Review(SLR) is a secondary study to map, identify, evaluate critically, consolidate and gathering major studies on specific research topics [3], SLR was a standard method to get answers by doing a literature review based on previous related studies. This literature review based on guidelines of systematic literature review proposed by Kitchenhand and Charters(2007) [4]. SLR consists of a three-stage process: planning, conducting and reporting reviews of the literature [5]. Planning stage performed 3 processes: identify the need, develop review protocol and evaluate review protocol. There are five processes in stage two that is search, select, extract data from primary studies, asses quality of primary studies and synthesize data. The last stage is a process to disseminate the result of the literature review.

The objective on this literature study is to understand the trends of research topics, methods, and architecture in decision-making with the GPS data. To get comprehensive results, the study took some literature published in the popular journal database that is IEEE Xplore, Scopus, ACM, and SpringerLink from 2010 to 2019.

\subsection{Research Question}

The purpose of the Research Question is to maintain the focus of the literature review. These conditions facilitate the search process needed data. Table 2 shows the research questions for this study.

Table 2. Research Question.

\begin{tabular}{cll}
\hline ID & \multicolumn{1}{c}{ Research Question } & \multicolumn{1}{c}{ Motivation } \\
\hline RQ1 & $\begin{array}{l}\text { Any topic of methods used in decision-making } \\
\text { with GPS data? }\end{array}$ & $\begin{array}{l}\text { Identification of methods used in decision making with } \\
\text { GPS data }\end{array}$ \\
RQ2 & $\begin{array}{l}\text { Any research trends in the decision-making with } \\
\text { GPS data? }\end{array}$ & $\begin{array}{l}\text { Identification of research trends in decision-making } \\
\text { with the GPS data. }\end{array}$ \\
RQ3 & The data used in decision making with GPS data? & $\begin{array}{l}\text { Identification of the data used in decision-making with } \\
\text { GPS data }\end{array}$ \\
\hline
\end{tabular}

\subsection{Research Result}

To answer Research Question already described above, the study does a search on the popular journal database with specific keywords for search. The key words are decision*AND "GPS data" AND (Method OR analy* OR technique OR trends). Search with those keywords performed in the abstract. Search results found as many as 3124 articles. Table 3 shows the results of the search process using those keywords. 
Table 3. Results Related Research.

\begin{tabular}{lll}
\hline No. & Database Journal & Number of Papers \\
\hline 1 & IEEE Xplore & 55 \\
2 & Scopus & 217 \\
3 & ACM & 13 \\
4 & SpingerLink & 2839 \\
\hline Total & & 3124 \\
\hline
\end{tabular}

Inclusion and exclusion criteria used to select the main research. The results of these articles of the criteria that will be reviewed by investigators. The inclusion and exclusion criteria are listed in Table 4.

Table 4. Criteria For Inclusion And Exclusion.

\begin{tabular}{lll}
\hline $\begin{array}{l}\text { Inclusion } \\
\text { criteria }\end{array}$ & I1 & $\begin{array}{l}\text { Articles related to trends, methods/techniques and architecture in } \\
\text { decision-making with GPS data }\end{array}$ \\
& I2 & $\begin{array}{l}\text { Articles are written in English } \\
\text { Articles can be accessed in full }\end{array}$ \\
& 3 & Artere \\
$\begin{array}{l}\text { Exclusion } \\
\text { criteria }\end{array}$ & E1 & The same article of the journal database of different \\
& E2 & $\begin{array}{l}\text { Articles in a book, conference, publication, conference review, or } \\
\text { white paper }\end{array}$ \\
& E3 & Journal articles that are not indexed Q1, Q2, and Q3 \\
\hline
\end{tabular}

In the first filtering, the criteria E1 \& I2 applied to the title and metadata section reduced the number of papers from 3124 to 959 . The second filtering, criteria E2 and years of paper reduced the number of papers to 754. The Third filtering, criteria full access applied makes the number of papers to 114. The last filtering, the criteria I1, E2, E3 to full-text review makes the number of papers to 27

After filtering with the inclusion and exclusion criteria in article search results using keywords then obtained several journal articles and conferences are shown in Table V. The number of articles acquired as many as 27 articles both journals and conferences. This article will be reviewed in this study.

Table 5. Results Filtering Process.

\begin{tabular}{lll}
\hline No. & Publication & number of Pages \\
\hline 1 & journal Q1 & 18 \\
2 & journal Q2 & 7 \\
3 & journal Q3 & 1 \\
4 & Journal Q4 & - \\
4 & Proceeding & 1 \\
\hline Total & & 27 \\
\hline
\end{tabular}

\section{Result}

\subsection{The Methods for Decision-Making with GPS Data}


There are several method for decision-making with GPS data. The method used can be algorithm or models. Differences in methods used are influenced by the condition of the data used, the cases discussed and the objectives of the study. Table 6 shows list of method for decision-making with GPS data.

Table 6. Methods For Decision-Making With GPS Data.

\begin{tabular}{|c|c|c|}
\hline No. & Methods & Publication \\
\hline 1 & Decision tree & {$[6][7][8][9][10][11][12]$} \\
\hline 2 & Random Forest & {$[11][12],[13][14][15]$} \\
\hline 3 & K-Nearest Neighbour & {$[11][12][16][17]$} \\
\hline 4 & Proposed method & {$[18][19][20][7][21]$} \\
\hline 5 & ARIMA-based method & {$[22][7][23]$} \\
\hline 6 & Poisson Model & {$[22]$} \\
\hline 7 & Neural Network & {$[7][12]$} \\
\hline 8 & Support vector machine & {$[7][11][12][13]$} \\
\hline 9 & Density-Based Spatial Clustering & [24] \\
\hline 10 & Statistical method & {$[8][14][25][26][27][28]$} \\
\hline Total & & 27 \\
\hline
\end{tabular}

The results show that the decision tree method is most widely used in decision making using GPS data. Another method that is often used after the decision tree is a random forest method. This shows that graph-based method is a very effective method used for decision making with GPS data.

In the case of validating the process of collecting data in a survey, several methods will be used at the stage of pre-processing the data and determining the results of the decisions to be taken. At the pre-processing data, the researcher will use statistical methods such as normal testing and smoothing data. To make a decision one method that produces the highest best fit will be chosen between the support vector machine, random forest, and decision tree. Three methods were chosen because these methods have high performance in terms of predictive analysis (classifying data).

\subsection{The trend in decision-making with GPS Data}

Various researchers have studied the application of GPS data analysis to make a decision. The application of decision making with GPS data is very diverse for various fields of business such as health, transportation, and environment as well as helping human daily activities. Table VII shown several application of decision-making with GPS data in various field.

Table 7. Trend Of Decision-Making With GPS Data.

\begin{tabular}{lll}
\hline No. & Field & Publication \\
\hline 1 & Health & {$[16][28]$} \\
2 & Agriculture & {$[10][27]$} \\
3 & Transport mode & {$[6][7][11][12][20][21][13]$} \\
4 & Traffic & {$[16][24][17]$} \\
5 & Human behaviour & {$[18][8][9][19][22][23][26][15]$} \\
\hline No. & Field & Publication \\
\hline 6 & Environtment & {$[25][14][29][30][31]$} \\
\hline Total & & 27 \\
\hline
\end{tabular}


GPS data analysis was initially only used to make decisions in the field of transportation such as determining the mode of transportation and managing traffic congestion. However, with the development of information technology, in particular, the increasing use of the Internet of Things (IoT), various businesses in various fields of life are using GPS data analysis to make decisions.

The health sector uses GPS data analysis to monitor patients and measure health indicators. Agriculture for monitoring livestock and monitoring plant growth. Field of environment for wildlife conservation and observation of environmental conditions.

GPS data analysis is also used to see how human behavior in everyday life such as determining human activities and activities, use of time, human movement patterns (travel destinations, travel paths and estimates of favorite places).

To validate the process of collecting data in a GPS data analysis survey, it is used to view the behavior of surveyors when conducting data collection. The behavior of the surveyor will then be used to make a decision whether the data for which the data collection process is conducted by the surveyor is valid (according to the SOP).

\subsection{The Data Used in Decision-making with GPS Data}

GPS data has a lot of content such as location, time, track, speed, etc. The data used for decision-making according the purpose of the study and method used. Table 8 shown several variable/data that analyzed for decision-making.

Table 8. Data Used In Decision-Making With GPS Data.

\begin{tabular}{lll}
\hline \multicolumn{1}{c}{ No } & \multicolumn{1}{c}{ Data } & \multicolumn{1}{c}{ Publication } \\
\hline 1 & Latitude longitude data & {$[18][7][8][10][13][17][20][19][21][22][23][24]$} \\
& & {$[27][28][29][30][32][31]$} \\
2 & Time Data & {$[18][6][7][8][10][14][19][20][21][22][24][30]$} \\
3 & Track/trajectory data & {$[18][7][11][25][31]$} \\
4 & Heading data & {$[6][16][17]$} \\
5 & Speed data & {$[6][11][12][13][14][15][20][24][31]$} \\
6 & Transportation data & {$[7][21][22][31]$} \\
7 & Distance & {$[18][12][14][15][19][23][28][31]$} \\
8 & Behaviour & {$[18][10][14]$} \\
\hline Total & & 27 \\
\hline
\end{tabular}

Position and time data are the most used data in terms of decision making using GPS data. Position data is the data of the existence of an object at a location indicated by latitude and longitude. Time data is a time that is used by an object of observation in moving from one place to another and the length of an observation object is stationary in a position. Then followed by data on speed, distance, and track.

In the validation study the process of collecting data in a survey, data on position, time, track (movement patterns) and individual surveyor data will be used to determine whether the data collection process has been carried out according to the SOP.

The study took the case of the national socio-economic survey (SUSENAS) conducted by the Central Statistics Agency (BPS). The SUSENAS data collection process consists of two stages, complete updating, and enumeration. Updating is the process of collecting initial data by visiting all prospective respondents in a survey environment. The updating results will be 
used as a basis for sampling. Complete enumeration is the process of collecting individual data from a complete sample according to the questionnaire used.

Decision support systems will be built to validate the process of collecting data in a survey built using the design research methodology (DRM) method. DRM consists of 4 processes, namely research clarification, descriptive study I, prescriptive study, and descriptive study II.

At the stage of research clarification, literature study, observation, and interviews were conducted to capture user needs. The interviews were conducted with the head of the BPS East OKU district and Head of IPDS of the BPS West Java Province. The results of this stage are shown in Fig. 2.



Fig. 2. Problem Model in the SUSENAS survey.

In the process of collecting data on SUSENAS, there were 4 main problems, namely limited enumeration time with a large number of respondents; Surveyors apply fraud by not coming to the respondent; There is a lot of supervision, one supervisor oversees 3 respondents; The does not have clear measurement tools. When the supervisor does not accompany the surveyor, the quality of the data collection process cannot be measured.

All of the above factors will affect the quality of the questionnaire content. Cases are usually found at the data processing stage where the questionnaire is not filled in completely and the data is inconsistent so re-data collection is needed. This will make the survey implementation schedule disrupted and result in the quality of the resulting data being reduced (non-sampling error).

The next step is a descriptive study I where the solution design is made based on the requirements collected. SLR is used as input material in preparing solutions. The design of the solution is shown in Fig. 3.

The proposed solution uses GPS data analysis and analysis of enumeration time. Then a decision support system is made to make a decision whether the data collection process is in accordance with the existing SOP. With the existence of DSS, analysis of GPS data and analysis of enumeration time, it is expected that all factors that cause reduced quality of questionnaires and quality of data can be resolved.

Next step is selecting methods used to analyze the data. Based on the four methods proposed, one method will be chosen which is best used in the validation of the process of collecting data in a survey. The selection based on the accuracy table in each method. Characteristics of several methods can be seen in the table 9 . 


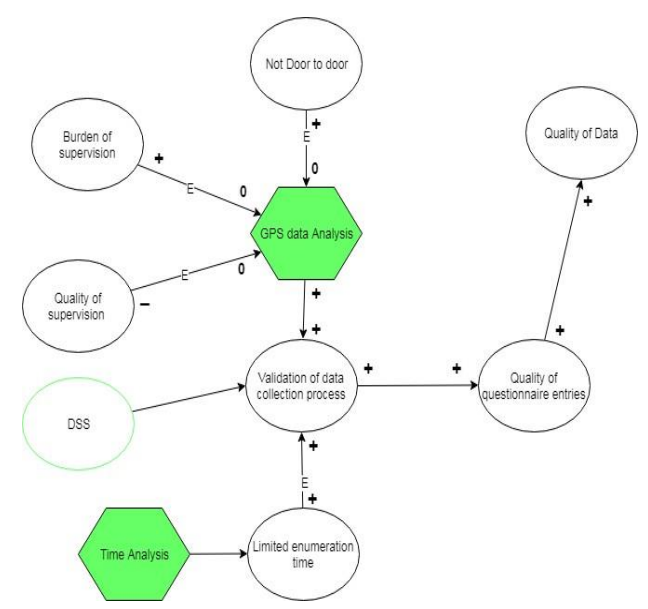

Fig. 3. Solution Model in the SUSENAS survey.

Table 9. Characteristic of MeThod.

\begin{tabular}{|c|c|c|c|}
\hline & Support Vector machine & Decision Tree & Random Forest \\
\hline Explanation & $\begin{array}{l}\text { Models with associated } \\
\text { learning algorithms that } \\
\text { analyze data used for } \\
\text { classification, regression } \\
\text { analysis, outlier detection. }\end{array}$ & $\begin{array}{l}\text { One classification method } \\
\text { that uses hierarchical } \\
\text { structures used for explore } \\
\text { data, find hidden } \\
\text { relationships between } \\
\text { variables }\end{array}$ & $\begin{array}{l}\text { algorithm used in the } \\
\text { classification of large } \\
\text { amounts of data(combine } \\
\text { many decision trees into a } \\
\text { single model) }\end{array}$ \\
\hline Type & supervised learning & supervised learning & supervised learning \\
\hline $\begin{array}{l}\text { Related } \\
\text { publication }\end{array}$ & $\begin{array}{l}{[11],[15]} \\
{[16],[17]}\end{array}$ & $\begin{array}{l}{[10],[11],[12],} \\
{[13],[14],} \\
{[15],[16]}\end{array}$ & $\begin{array}{l}{[15],[16],[17],} \\
{[18],[19]}\end{array}$ \\
\hline Accuracy & high Accuracy & Medium accuracy & high Accuracy \\
\hline Execution time & slow $\left(\mathrm{O}\left(\mathrm{N}^{\wedge} 2\right)-\mathrm{O}\left(\mathrm{N}^{\wedge} 3\right)\right)$ & $\operatorname{slow}\left(\mathrm{O}\left(\mathrm{N}^{\wedge} 2 \mathrm{p}\right)\right.$ & $\operatorname{slow}\left(\mathrm{O}\left(\mathrm{N}^{\wedge} 2 \mathrm{pN}\right)\right.$ \\
\hline Data & $\begin{array}{l}\text { Requires full labeling of } \\
\text { input data, polynomial }\end{array}$ & $\begin{array}{l}\text { Non Parametric Method, } \\
\text { high chance of over fitting }\end{array}$ & $\begin{array}{l}\text { high dimensional data, } \\
\text { high variance, but low } \\
\text { bias }\end{array}$ \\
\hline $\begin{array}{l}\text { Can be real time } \\
\text { process }\end{array}$ & Yes & Yes & Yes \\
\hline
\end{tabular}

After the method was chosen, the rest of our research will continue with previous research, find something that is a contribution from research comparison of several studies with research on the validation of the enumeration process in a survey can be seen in table 10 .

Table 10. Research Positioning.

\begin{tabular}{|c|c|c|c|c|}
\hline & $\underset{(2011)}{J u n}$ & $\begin{array}{l}\text { Arijit Chowdhury } \\
\text { (2018) }\end{array}$ & $\begin{array}{l}\text { Zong Fang } \\
(2017)\end{array}$ & $\begin{array}{l}\text { You Ari Faeni } \\
(2019)\end{array}$ \\
\hline Research & Time activity & Investigte driver & Identify activities & Validation of data \\
\hline Objectives & Classification & unique identity & and trip & collection process \\
\hline Data & Speed, Time, location & $\begin{array}{l}\text { Distance, speed, total } \\
\text { trip(time) }\end{array}$ & $\begin{array}{l}\text { Location, time } \\
\text { distance }\end{array}$ & $\begin{array}{l}\text { Location, time, } \\
\text { track, dsitance, } \\
\text { individual data }\end{array}$ \\
\hline
\end{tabular}




\begin{tabular}{|c|c|c|c|c|}
\hline & $\begin{array}{l}\text { Jun Wu } \\
(2011)\end{array}$ & $\begin{array}{l}\text { Arijit Chowdhury } \\
\text { (2018) }\end{array}$ & $\begin{array}{l}\text { Zong Fang } \\
(2017)\end{array}$ & $\begin{array}{l}\text { You Ari Faeni } \\
(2019)\end{array}$ \\
\hline $\begin{array}{l}\text { Research } \\
\text { Process }\end{array}$ & $\begin{array}{l}\text { Data cleaning } \\
\text { Data analysis }\end{array}$ & Data analysis & $\begin{array}{l}\text { Data Pre- } \\
\text { processing } \\
\text { Data analysis }\end{array}$ & $\begin{array}{l}\text { Data Collection } \\
\text { Data pre- } \\
\text { processing } \\
\text { Data Analysis }\end{array}$ \\
\hline $\begin{array}{l}\text { Analysis } \\
\text { method }\end{array}$ & Random forest & $\begin{array}{l}\text { Macro average } \\
\text { precision, svm, KNN }\end{array}$ & $\begin{array}{l}\text { Statistical } \\
\text { method }\end{array}$ & $\begin{array}{l}\text { Svm, decision tree, } \\
\text { random forest, } \\
\text { neural network }\end{array}$ \\
\hline Accuracy & $80 \%$ & $74 \%$ & $\mathrm{n} / \mathrm{a}$ & $85 \%$ \\
\hline
\end{tabular}

Table 10 shows comparison of several study in decision-making with GPS data to analyze human behavior. Jun wu classify time activity such as indoor, outdoor static, outdoor walking, and in-vehicle travel. Arijit investigate driver unit identification to identify the driver that drive a vehicle. Zong fang identify activities and trip of human by providing the identification method of short time activities. Study of validation of collection data in a survey will used location, time, track, distance and individual data of surveyor. Target accuracy of questionnaire entries is $85 \%$. Three method will be compare to analyze GPS data. Best result will be applied in the system.

This decision-making framework propose a method to validate process of data collection in a probability sampling survey using the GPS data. Surveyors smartphone run the application that record the GPS data according the place they visit. Position, time, track and direction will be recorded according to the rules set. In the case of SUSENAS, the rule that will be used when updating is if the surveyor stops at a location/moves within a radius of 5 meters in more than 1 minute, then the location and length of time stopped will be recorded. In the complete enumeration activity the rules used are if the surveyor stops at a location/moves within a 5-meter radius in more than 30 minutes, then the location and length of time the stop will be recorded.

The next stage is the analysis phase which will later be determined whether the system will make a recommendation whether the enumeration is valid, doubtful, or invalid. The data will be processed based on the rules given by the experts and the results of interviews with supervisors and field enumerators.

\section{Conclusion}

The results of the Systematic Literature Review show several methods, trends and data used to make decisions with GPS data. Based on the result of SLR this study is a proposed method to validate data collection in a survey by using 3 method (SVM, decision tree, and random forest), this method will use position, time, track and personal data of the surveyor with the target accuracy $85 \%$ to reduce the error of questionnaire entries. The next study will be conducted to validate the process of collecting data in the national socio-economic survey (SUSENAS) at the Statistics of Indonesia (BPS). 


\section{References}

[1] UU no 16 tahun 1997, "Undang - undang no 16 tahun 1997 tentang Statistik," (1997)

[2] J Supranto, "Statistika Teori dan Aplikasi, edisi ketujuh," 2008, Vol. 27, No. erlangga, (2008)

[3] A. Dresch, D. Pacheco, L. Jos, V. A. Jr, and T.: Advancement, Design Science Research: A method for Science and Technology Advancement. Springer International Publishing Switzerland, (2015)

[4] S. Kitchenham, B., and Charters.: "Guidelines for performing systematic literature reviews in software engineering." (2007)

[5] R. S. Wahono.: "Services \& Rate Agreement Services \& Rate Agreement," A Syst. Lit. Rev. Softw. Defect Predict. Trends, Datasets, Methods Fram., Vol. 1, No. 1, pp. 3-5, (2015)

[6] Y. Chen.: "Understanding Transportation Modes Based on GPS Data for Web Applications," Vol. 4, No. 1 (2010)

[7] X. Kong, F. Xia, J. Wang, A. Rahim, and S. K. Das.: "Time-Location-Relationship Combined Service Recommendation Based on Taxi Trajectory Data," IEEE Trans. Ind. Informatics, Vol. 13, No. 3, pp. 1202-1212 (2017)

[8] J. Wu, C. Jiang, D. Houston, D. Baker, and R. Delfino.: "Automated time activity classification based on global positioning system (GPS) tracking data," Environ. Heal. A Glob. Access Sci. Source, Vol. 10, No. 1 (2011)

[9] X. Chen et al.: "Data-driven prediction system of dynamic people-flow in large urban network using cellular probe data," J. Adv. Transp., Vol. 2019 (2019)

[10] N. De Weerd et al.: "Deriving animal behaviour from high-frequency GPS: Tracking cows in open and forested habitat," PLoS One, Vol. 10, No. 6, pp. 1-17 (2015)

[11] Z. Xiao, Y. Wang, K. Fu, and F. Wu.: "Identifying different transportation modes from trajectory data using tree- based ensemble classifiers," ISPRS Int. J. Geo-Information, Vol. 6, No. 2 (2017)

[12] H. Zheng, Z. Cui, and X. Zhang.: "Identifying modes of driving railway trains from GPS trajectory data: An ensemble classifier-based approach,” ISPRS Int. J. Geo-Information, Vol. 7, No. 8 (2018)

[13] Z. Zhou, J. Yang, Y. Qi, and Y. Cai.: "Support vector machine and back propagation neutral network approaches for trip mode prediction using mobile phone data," IET Intell. Transp. Syst., Vol. 12, No. 10, pp. 1220-1226 (2018)

[14] J. Peter et al.: "Intercomparison and Validation of SAR-Based Ice Velocity Measurement Techniques within the Greenland Ice Sheet CCI Project," (2018)

[15] A. Chowdhury, T. Chakravarty, A. Ghose, T. Banerjee, and P. Balamuralidhar.: "Investigations on Driver Unique Identification from Smartphone's GPS Data Alone,” J. Adv. Transp., vol. (2018)

[16] F. Munyaneza et al.: "Leveraging community health worker system to map a mountainous rural district in low resource setting: A low-cost approach to expand use of geographic information systems for public health,” Int. J. Health Geogr., Vol. 13, No. 1 (2014)

[17] L. Fan, L. Tang, and S. Chen.: "Optimizing location of variable message signs using GPS probe vehicle data," PLoS One, Vol. 13, No. 7 (2018)

[18] Z. Fang, L. Jian-yu, W. Xiao, T. Jin-jun, and G. Fei.: "Identifying activities and trips with GPS data," IET Intell. Transp. Syst., Vol. 12, No. 8, pp. 884-890 (2018)

[19] L. Wang, Y. Zhong, and W. Ma.: "GPS-data-driven dynamic destination prediction for ondemand one-way carsharing system," (2018)

[20] Z. Tian et al.: "Real-Time Charging Station Recommendation System for Electric-Vehicle Taxis,” IEEE Trans. Intell. Transp. Syst., Vol. 17, No. 11, pp. 3098-3109 (2016)

[21] W. Tu, Q. Li, Z. Fang, S.-L. Shaw, B. Zhou, and X. Chang.: "Optimizing the locations of electric taxi charging stations: A spatial-temporal demand coverage approach," Transp. Res. Part C Emerg. Technol., Vol. 65, pp. 172-189 (2016)

[22] L. Moreira-matias, J. Gama, M. Ferreira, J. Mendes-moreira, and L. Damas, "Predicting Taxi Passenger Demand Using Streaming Data," Vol. 14, No. 3, pp. 1393-1402 (2013) 
[23] A. J. King et al., "Social density processes regulate the functioning and performance of foraging human teams," Sci. Rep., Vol. 5 (2015)

[24] Y. Liu, X. Yan, Y. Wang, Z. Yang, and J. Wu.: "Grid mapping for spatial pattern analyses of recurrent urban traffic congestion based on taxi GPS sensing data," Sustain., Vol. 9, No. 4 (2017)

[25] M. C. Benedetti, G. D. Omo, T. Russo, C. Catoni, and P. Quillfeldt.: "Interactions between commercial fishing vessels and a pelagic seabird in the southern Mediterranean Sea," BMC Ecol., (2018)

[26] R. Pérez-Torres, C. Torres-Huitzil, and H. Galeana-Zapién.: "A cognitive-inspired event-based control for power- aware human mobility analysis in IoT devices," Sensors (Switzerland), Vol. 19, No. 4 (2019)

[27] K. Zhou, A. L. Jensen, D. D. Bochtis, and C. G. Sørensen.: "Performance of machinery in potato production in one growing season," Spanish J. Agric. Res., Vol. 13, No. 4 (2015) 